Studia Anglica Posnaniensia 50/2-3, 2015

doi: $10.1515 /$ stap-2015-0020

\title{
AFFECT AND NOSTALGIA IN EVA HOFFMAN'S LOST IN TRANSLATION
}

\author{
ELIZABETH KELLA
}

Södertörn University

\begin{abstract}
This article examines the affective terrain of Poland, Canada, and the US in Eva Hoffman's autobiographical account of her migration and exile in Lost in Translation: A Life in a New Language (1989), the text that launched Hoffman's reputation as a writer and intellectual. Hoffman's Jewish family left Poland for Vancouver in 1959, when restrictions on emigration were lifted. Hoffman was 13 when she emigrated to Canada, where she lived until she went to college in the US and began her career. Lost in Translation represents her trajectory in terms of "Paradise," "Exile," and "The New World," and the narrative explicitly thematizes nostalgia. While Hoffman's nostalgia for post-war Poland has sometimes earned censure from critics who draw attention to Polish anti-Semitism and the failings of Communism, this article stresses how Hoffman's nostalgia for her Polish childhood is saturated with self-consciousness and an awareness of the politics of remembering and forgetting. Thus, Hoffman's work helps nuance the literary and critical discourse on nostalgia. Drawing on theories of nostalgia and affect developed by Svetlana Boym and Sara Ahmed, and on Adriana Margareta Dancus's notion of "affective displacement," this article examines Hoffman's complex understanding of nostalgia. It argues that nostalgia in Lost in Translation is conceived as an emotion which offers the means to critique cultural practices and resist cultural assimilation. Moreover, the lyricism of Hoffman's autobiography becomes a mode for performing the ambivalence of nostalgia and diasporic feeling.
\end{abstract}

Keywords: autobiography, nostalgia, migration, immigration, exile, affect, lyric

"Writing about the loss of home brings one home again. You can't go home againexcept in writing home. The rapture of writing rupture." (Friedman 2004: 207)

In contemporary discourse, "nostalgia" retains a negative charge. It is an ascriptive term of censure, accusatory, signaling a malady, a memory clouded by sentiment, a failure of intellect. Nostalgia is frequently said to be innately conservative, even reactionary; it is an irrational longing directed toward regaining an idealized and 
essentialized past. "Nostalgia," writes Svetlana Boym, "is something of a bad word, an affectionate insult at best" (2001: xiv). Olivia Angé and David Berliner sum up: "Long seen as a malaise, as 'bad history,' nostalgia was often attacked for its sentimentalism and historical falsification, and it still is" (2015: 5). For Polish émigré writer Eva Hoffman, nostalgia - "the first temptation of exile" - can be "a very lyrical emotion" which can run the risk of turning into "melancholic mourning" for a romanticized, unchanging, and unchangeable past (Hoffman 2006: 14). ${ }^{1}$ Not just bad history, nostalgia can become a "bad feeling" as well.

For a writer such as Hoffman, whose parents evaded the worst terrors of the Holocaust only to escape new forms of anti-Semitism after WW II by emigrating to Canada with Ewa and her younger sister, nostalgia for Poland would appear to be impossible. Certainly, many critics of Hoffman's 1989 autobiography, Lost in Translation: A Life in a New Language, have insisted that nostalgia should be impossible. Marianne Hirsch reads Hoffman against her own experiences of emigration from Romania, and objects to "the pervasive nostalgia that clings to everything Polish" (1994: 76). She sees Hoffman as in denial about gender regimes and anti-Semitism in postwar Poland. Hirsch is clear about her difference from Hoffman: "I identify neither with Hoffman's nostalgically Edenic representation of Poland, nor with her utter sense of dispossession later, nor do I share her desperate desire to displace the relativity, the fracturing, the double-consciousness of immigrant experience" (1994: 77). Because of Polish anti-Semitism, Barbara R. Gitenstein argues, Hoffman's (primary) identification as Polish is at fundamental odds with her (secondary) Jewish identity, and Hoffman must therefore engage in forms of "self negation" (1997: 265). Eva Karpinski is critical of Hoffman's nostalgia and her failure to maintain an exilic, outsider status after immigration (Macpherson 2008: 100). Madeline Levine's criticism is severe. She states that "at some deep level Eva Hoffman did not want to know about the Holocaust, did not want to acknowledge the complications her Jewishness would certainly have caused her had she remained in Poland. Her passionate attachment to her idealized image of Cracow, her loyalty to Polish culture, seem part and parcel of this avoidance" (Levine 2003: 227). She summarizes Lost in Translation thus: "All in all, this is a very flattering self-portrait of a super-achiever who knows she is terrific but who still, like the insecure immigrant child at her core, keeps on struggling to prove it" (Levine 2003: 225).

1 The link between nostalgia and exile may have a particular inflection for Eastern and Central Europeans. Maria Todorova wonders if post-Communist nostalgia is like "free-world nostalgia" (2010: 2) and suggests that research on post-Communist Europe strongly privileges the idea of reassessing and coming to terms with the past. Halina Stephan observes that the end of the Cold War collapsed the category of exile to replace it with ideas of migration and diaspora. Postmodern understandings of exile as "a natural condition in a modern multicultural setting" (2003: 15), she argues, fail to "address the particular exile experience of the writers from the socialist Eastern Europe" (2003: 16). 
While Hoffman's text clearly has its detractors, it also has those who extol its merits. Some critics explicitly argue against the idea that the autobiography is invested in an immigrant success story, or against the idea that Hoffman privileges a notion of unitary identity. Stanislaw Baranczak refers to it as a semiotic memoir (1990: 224), and Danuta Zadworna Fjellestad calls it "the first "postmodern' autobiography written in English by an émigré from a European Communist country" (1995: 136). Lost in Translation has been most widely praised for its exploration of the linguistic and cultural construction of identity. Many critics approve Hoffman's self-conscious narration, finding that her self-reflexivity prevents her from succumbing to at least the crudest forms of essentialism. Few critics, however, have scrutinized nostalgia as it emerges in the text, even though, in its self-conscious deployment of the concept, Lost in Translation contributes to a literary and critical discourse which seeks to nuance understandings of nostalgia, locating in the concept some progressive potential.

In critical discourse, some attempts have been made to understand nostalgia differently, or to theorize different types of nostalgia. As Sean Scanlan observed in 2004, "cultural critics are beginning to understand that nostalgia is always complicated (. . .)" (3). Angé's and Berliner's (2015) recent assessment of anthropology's relations to nostalgia stresses how nostalgia emerges in response to real or imagined threats to continuity, but above all, how multiple and various nostalgic desires may be. Rough typologies tend to set up contrastive notions. Frederic Jameson distinguishes between different expressions of nostalgia, decrying the evacuation of a strong sense of historicity in the postmodern aesthetics of nostalgia (1991: xvii). Maria Todorova insists that, in its best forms, nostalgia can refer to "an activist critique of the present using the past as a mirror" (2010: 7). Marianne Hirsch and Leo Spitzer concur: nostalgia may refer not only to an "indiscriminate idealization of past time and lost place," but also "more positively, as a resistant relationship to the present, a 'critical utopianism' that imagines a better future" (2002: 258). Nostalgia can take a negative form which, in positing a more "authentic" self, can hamper the development of immigrant identity, but, argues Andrea Deciu Ritovoi, it can also take a positive form which offers "an interpretive stance in which a person is aware of the element of discordance in her life" (qtd in Herman 2005: 360). Boym (2001), explicitly interested in the condition of exile and how it can give rise to nostalgia, distinguishes between "restorative" and "reflective" nostalgia. She considers restorative nostalgia to be evocative of an ideal home or nation, an origin, gravitating toward collective symbolism and oral tradition. Reflective nostalgia, by contrast, focuses on history and the passage of time, on individual and cultural memory, but always defers homecoming. While Boym's distinctions can be helpful in considering Hoffman's work, these binaries have been critiqued for neglecting the range of 
emotions associated with migration, exile, and diaspora. Adriana Margareta Dancus (2011) stresses instead "affective displacement" and "diasporic feeling," categories which include nostalgia, but are not limited to it.

In this article, I draw on Boym, Dancus and Sara Ahmed's work on affect to examine Hoffman's self-conscious treatment of nostalgic desire. Rather than dwelling on the question of whether nostalgia is a "good" or "bad" feeling, I consider the uses and functions of nostalgia in this work, focusing on the somewhat neglected account of her immigrant experience in Canada, as well as on the much discussed conclusion of the novel. In Eva Hoffman's autobiography, I argue, nostalgia is a complex emotion which functions as a resource for resistance to assimilation, and which animates her writing and aesthetic choices. A manifestation of affective displacement, the to-and-fro motions of nostalgia in Lost in Translation structure Eva's emotional, cultural, linguistic, and finally artistic alignments, and infuse her narrative with a lyricism which performs many of the ambivalences of diasporic feeling.

Hoffman's autobiography launched her reputation as a writer and intellectual. ${ }^{2}$ Lost in Translation covers her childhood in post-war Cracow, her emigration to Vancouver with her family in 1959, when Hoffman was 13, and her college years and early adult life in the US. The autobiography is divided into three parts: "Paradise," "Exile," and "The New World," each part corresponding, respectively, to Poland, Canada, and the US. Critics have made much of these sections, examining the way they adhere to or challenge conventions of immigrant autobiography, and, as we have seen, questioning the association of post-war Poland with "Paradise." The tendency to focus, then, on Poland and the US, has caused the section of the novel which has to do with Canada to be somewhat overlooked. Few critics give weight to Hoffman's emigration to Canada, possibly because the "Exile" section is shorter than the other sections, both in terms of pages, and in terms of the time it covers, and possibly because Hoffman herself tends to subsume Canada into "America," "North America," or "The New World"-both in Lost in Translation and in subsequent writings and interviews. ${ }^{3}$ Against that trend, Sarah Phillips Casteel examines Hoffman's construction of Canada as a "locus of Holocaust memory" (2001: 293) and Heidi Slettedahl Macpherson analyses what she calls "Hoffman's transitional Canadianness" (2008: 91) in the context of transnational literature. Here, I pay particular attention to the exilic period in Canada, viewing it as foundational rather than transitional. It is in Canada that Ewa is renamed Eva,

2 Levine portrays Hoffman as cannily exploiting her knowledge of publishing and the interest in Poland created by the Solidarity movement in the 1980s to achieve success.

3 For example, Hoffman reflects that the "self that is the most American thing about me" has been acquired "here" (1998 [1989]: 251), with the entire scene set in Vancouver. Phillips Casteel stresses how the three-part structure of the work draws sharp distinctions in culture- or nationbased identity, but the narrative does not stay neatly within the geographical or temporal boundaries of the structure. 
precipitating an identity crisis that is inseparable from a crisis in language. ${ }^{4}$ Moreover, it is in Canada that Eva most actively resists assimilation, amassing her resistance around nostalgic or diasporic feelings. Finally, it is in Canada that Eva's formation as an artist and autobiographer/diarist is set into motion.

Although homesickness and expressions of nostalgia emerge most prominently in the "Exile" section, the opening of Lost in Translation overtly establishes nostalgia as a theme. Beginning not with a scene of arrival, as we might expect from an immigrant autobiography, but with a scene of departure, from Poland, Hoffman proffers the Polish word, tesknota, as a replacement for nostalgia; tęsknota "adds to nostalgia the tonalities of sadness and longing" (Hoffman 1998 [1989]: 4). ${ }^{5}$ Hoffman renders Ewa's first "acute" experience of nostalgia in a manner that stresses embodiment: the embodiment of sorrow, pain, grief, anger, and resentment. Already at a remove from home, on a boat in the harbor in Gdynia, she hears the Polish anthem and is "pierced by a youthful sorrow so powerful" that she stops crying and tries to "hold still against the pain" (1998 [1989]: 4). Here, Hoffman underscores that longing for home is "the body's desire - a feeling of homesickness experienced viscerally in the flesh, in the "affective body" (Friedman 2004: 191). Indeed, the first sentence of Lost in Translation describes young Ewa's feeling that her "life is ending," and the first paragraph concludes that "to me it might as well mean the end of the world" (1998 [1989]: 3). While readers might take this description as simple hyperbole, appropriate to the uprooted, teen-aged self that is under textual reconstruction, a subsequent passage in the first chapter clearly underscores Ewa's powerful awareness of the irretrievable passage of time. Ewa recalls walking home from school in Cracow, aware of nothing but the moment: "But, suddenly, time pierces me with its sadness. This moment will not last. With every step I take, a sliver of time vanishes" (1998 [1989]: 16). Her feeling produces an intimation of mortality: "How many moments do I have in life? I hear

$4 \quad$ As a convenient reminder of the distinction between the narrating "I" and the narrated "I" of autobiography, as well as the twin "I"s created in the text, I refer to Hoffman as the narrating I and Ewa or Eva to refer to the textual personas. The personas of Ewa and Eva are not clear-cut.

5 The English term was coined by a Swiss doctor in 1688, combining the Greek "nosta," meaning "return home" and "algia", meaning "longing." The word has come to mean longing for a lost home, and thus it encompasses feelings of exiles, migrants, immigrants, emigrants, diasporic peoples, and other displaced individuals. Boym's binary typology derives from the units of this compound: "Restorative nostalgia stresses nostos and attempts a transhistorical reconstruction of the lost home. Reflective nostalgia thrives in algia, the longing itself, and delays the homecoming - wistfully, ironically, desperately. Restorative nostalgia does not think of itself as nostalgia, but rather as truth and tradition. (. . .) Restorative nostalgia protects the absolute truth, while reflective nostalgia calls it into doubt" (2001: xviii). In Boym's binary system, the usual negative connotations of nostalgia are clearly the province of restorative nostalgia, and critical insight is reserved for reflective nostalgia. 
my own breathing: with every breath, I am closer to death" (1998 [1989]: 17). She goes on: "I slow down my steps: I'm not home yet, but soon I will be, now I am that much closer, but not yet . . . not yet. . not yet . . . Remember this, I command myself, as if that way I could make some of it stay. When you're grown up, you'll remember this. And you'll remember how you told yourself to remember" (1998 [1989]: 17, original ellipses). This passage underscores the young girl's experience and insight into loss, and her understanding of memory as a way of countering loss, even if only imaginatively: she recognizes even in the moment that it is as if memory, and telling, can hold the fullness of time and an undivided self. Thus, the opening of Hoffman's autobiography registers a desire for full presence, but also its impossibility. Only through memory, andsince we have the later, written account - through the literary and lyrical representation of memory, can this semblance of plenitude exist.

The representation of post-war Poland as an object of nostalgic desire is thus consistently characterized by acute self-consciousness, a Jamesonian awareness of the historicity of the present, or at least of the way that the present may anticipate and register both loss and remembrance. Nevertheless, as we have seen, Hoffman's representations of positive memories of Poland have been questioned. Hirsch, for example, asks: "What does it take for Hoffman to consider [Poland] paradise? Why would she want to recapture a childhood that rests on such [an anti-Semitic] legacy? (. . .) With her evocation of childhood plenitude, Hoffman has displaced the reality of the war, of the anti-Semitism she admittedly still experiences, (. . .) " (qtd MacPherson 2008: 94). Such objections, in fact, are generally anticipated as early as the third page of the autobiography, when Hoffman interrupts the narrative of childhood to relate that she would later marvel at her own ability to make a paradise out of "a lumpen apartment in Cracow, (. . .) surrounded by squabbles, dark political rumblings, memories of wartime suffering, and daily struggle for existence" (1998 [1989]: 5). In the "Exile" section the critique is explicitly anticipated: "It wasn't any good back there, our Jewish acquaintances say, why would you even want to visit, they didn't want you anyway. I hang my head stubbornly under the lash of this wisdom. Can I really extract what I've been from myself so easily? Can I jump continents as if skipping rope?" (1998 [1989]: 115). Similarly, in school in Canada, Eva is asked about life under Communism, and she insists there was freedom in communist Poland: "More so than here, maybe. Politics is one thing, but what good is freedom if you behave like a conformist, if you don't laugh or cry when you want to?" (1998 [1989]: 132). In these instances, Hoffman/Ewa defends neither anti-Semitism nor Communism, but reconstructs the young Ewa's feelings about and in her native country; she thus validates those feelings, in all their complexity. From the outset, then, the autobiography traces the remembered affect of emigration, affect here 
roughly defined as "something that moves, that triggers reactions, forces, or intensities (...), simultaneously engaging the mind and body, reason and emotions" (Berberich, Campbell and Hudson 2013: 314). In doing so, she reminds us that diaspora is "both about identity (who the displaced are) and affect (how the displaced feel)" (Dancus 2011: 250). ${ }^{6}$

Perhaps due to the autobiography's self-reflexive sophistication, or to our habits of reading for ideas, the centrality of emotions is easily overlooked. Yet, Eva's complex feelings of longing for and loyalty to her homeland are feelings commonly elicited by emigration or exile. In her history of homesickness in the US, for example, Susan Matt writes about Eastern European Jews before 1900, 15-20 percent of whom returned to their homelands: "Their experiences and emotions defied expectations and indicate that despite persecution, people could carve out a home and sense of place in the midst of an oppressive society. Although they were treated as outsiders in Lithuania, Russia, and Poland, many Jews still considered such places home, and found that America, with its vaunted opportunities and liberties, was alien" (2011: 145). WW II, of course, took the persecution and oppression of Jews and other stigmatized groups to the horrific levels of atrocity, and most of Poland's surviving Jewish population left Communist Poland when they could, as did Hoffman's family. ${ }^{7}$ Yet, clearly aware of the politics of remembering and forgetting the Holocaust and Communism, Hoffman does "stubbornly" give voice to Ewa's longing for Poland as a place and a culture in which she feels at ease, at home.

Dancus attributes a broad spectrum of emotions, including nostalgic desire, to the categories of "affective displacement" and "diasporic feeling." She characterizes diasporic feeling as an "analytic category" which is "concerned with the ways in which diasporas perform their difference, not primarily in relation to their lost homeland but in response to the host country's institutions, discourses, practices, and the official national affect that supports them" (Dancus 2011: 250, my italics). ${ }^{8}$ She observes that "Diasporas long for the lost home at the same time they love, hate, hope, fear, panic, resent, envy, mourn, cheer, complain, etc.,

6 Hoffman's position mobilizes but also unsettles categories such as "immigrant," "emigrant," "exile," "diaspora," or, as she writes late in the text, "resident alien" (1998 [1989]: 251). To my mind none of these categories is completely satisfactory.

7 In her autobiography, Hoffman explains that her family comes to Canada at an odd time (1998 [1989]: 125); she also relates how the lifting of emigration bans in 1956 and later, in 1968, led to the exodus of most of Poland's remaining Jews.

$8 \quad$ For Dancus, "diasporic feeling facilitates an understanding of diasporas as affective displacements not in a vacuum or some kind of equilibrium, but in a specific locale where global and national meet in a contingent way and power relations are very much at stake" (2011: 250). What Dancus does not take up as much is the way in which diasporic feeling is also about how immigrants may attempt to perform their sameness, may "obey" the scripts and imperatives of immigration — but perform it in a way they and others may experience as inauthentic. 
within a different emotional register than the host country" (Dancus 2011: 250). In other words, diasporic feeling, including nostalgia, is not only about the past, but about the present. Diasporic feeling orients the subject not only toward the past, but also to the present place and time.

Hoffman's concern with the complexity of affective displacement and diasporic feeling is particularly prominent in the "Exile" section. She represents Ewa's entry into Canada as, in fact, both a severance and a rebirth. The train from Montreal to Vancouver travels through "endless expanses of terrain" (1998 [1989]: 100), cutting her life into two parts and inducing in Eva and her sister somatic responses once associated with the medical condition of nostalgia: extreme lethargy on Eva's part, and "a state of feverish illness" (Hoffman 1998 [1989]: 100) on her sister's. Three days after arriving in Vancouver, Eva has a nightmare which Hoffman figures as a "rebirth into the New World," a rebirth accompanied by a "primal scream" of terror. The terror emerges from knowing "what it is to be cast adrift in incomprehensible space" (1998 [1989]: 104), abandoned by her mother and father and, I would stress, by language itself: her "prolonged scream" displaces her native language. Initially, lethargy and terror are Eva's primary emotional responses to exile and migration.

Emotions are more than spontaneous feeling; as Sara Ahmed demonstrates, they are cultural practices, capable of being elicited by language use, that move or affect us in particular ways. Most importantly, affect helps align bodies with or against communities and ideologies. Throughout Hoffman's narrative, we can see how language moves Eva, and places her in different positions vis à vis different social groupings. This is especially so in the "Exile" section, which deals both with language and with strong, turbulent emotions. Using a different vocabulary, Ahmed analyzes the experience of alienation as a falling out of sync with an affective community: "When we feel pleasure from (. . .) objects [that circulate as social goods], we are aligned; we are facing the right way" (2010:37). It should be noted that the category of object here includes material objects but also less tangible units, such as values, practices, aspirations, and styles. Ahmed continues: "We become alienated — out of line with an affective community-when we do not experience pleasure from proximity to objects that are already attributed as being good" (2010: 37). ${ }^{9}$

This is precisely Eva's experience in Canada. From the first, as we have seen, Eva is indifferent to the spectacular natural landscape surrounding Vancouver: "It is the prevailing opinion of humankind that this is beautiful, breathtaking. But my

9 This resultant alienation, Ahmed writes, can give rise to "an anxious narrative of self-doubt ... or a narrative of rage" (2010: 37), with both narratives producing strangers or "affect aliens" (2010: 37). Hoffman's work contains both narratives, involving Eva's insecurities and sense of insufficiency, but also her "immigrant rage" (Hoffman 1998 [1989]: 203). 
soul does not go out to these spectacular sights, which reject me, because I reject them. I want my landscapes human sized and penetrable (. . .)." (Hoffman 1998 [1989]: 134).${ }^{10}$ But Eva also becomes out of line with, or alienated from, the Polish immigrant community in Vancouver. She fails to appreciate many of the "objects" these communities value - from the tasteless bologna and white-bread sandwiches she eats for lunch, to single-family dwellings to complex but insipid dating rituals. Ideas about femininity and heterosexual relations incur her most vehement critique. Introduced to new cultural norms by older women, Eva fears becoming, like each of them has, "a woman who has the comfort of living the perfectly knowable orderliness of middle-class convention" (Hoffman 1998 [1989]: 142-43). She recoils at "the rules and constraints of sexual behavior" explained by her Canadian friend, Penny, whose idea of love is diametrically opposed to Eva's: Penny envisions love as "running with someone through a sunny meadow, holding hands" while Eva imagines it as "a dark forest that you go into by a narrow path" (1998 [1989]: 147). This contrast suggests how the happiness of love might function in a culturally specific manner - a manner contingent, in Ahmed's scheme, upon a community's conferral of value on particular styles of emotion. ${ }^{11}$

Ahmed's choice of the phrase "being out of line" with an affective community is apt, for individuals who are implicitly or explicitly critical of the values of a given community may indeed be interpreted as "out of line." As a result, they may be thought in need of being disciplined, regulated, brought back into line, back into the fold. Ahmed considers, for example, the roles of "the feminist killjoy," "the angry black woman," and "the melancholic migrant"- all types of "affect aliens." 12 In "Exile," Eva occupies a similar role - that of the troubled teenager whose failure to align with the assimilative ideals of Canadians and the Polish community in Canada enables her to critique the values of that community: their material and marital gains so essential to "the immigrant success story" which they-in contrast to Eva-accept. ${ }^{13}$

10 Phillips Casteel's analysis of "double emigration" connects different modes of memory to the different countries Hoffman lives in. Hoffman's negative portrayal of the Canadian environment, she argues, has to do with psychological process of projection and the symbolic containment of Holocaust memory.

11 Looking at a photo of herself taken one year after her arrival in Canada and after her "makeover" by older Polish immigrant women, Hoffman sees that "alienation" is written on her body, identifiable in her "clumsy" appearance, her shoulders "bent with the strain of resentment and ingratiation..." (Hoffman 1998 [1989]: 110).

12 Ahmed's term "affect alien" resonates with Hoffman's ironic inflection of the term "resident alien," in the "New World" section of the memoir.

13 Ahmed observes that "Some bodies are presumed to be the origin of bad feeling insofar as they disturb the promise of happiness, which I would re-describe as the social pressure to maintain the signs of 'getting along"' (2010: 39). She notes that such bodies become "blockage points, points where smooth communication stops" (2010: 39), and in this blockage issues of power 
Significantly, however, Hoffman imagines that another story is also possible: "(. . .) perhaps, if they had the words to say just what they feel, something different might pour out, an elusive complaint of an elusive ailment. For insofar as meaning is interhuman and comes from the thickness of human connections and how richly you are known, these successful immigrants have lost some of their meaning. In their separateness and silence, their wisdom - what they used to know in an intimate way, on their skin -is stifled (. . .)." (1998 [1989]: 143). This passage gives voice to a deeply humanist perspective, at the same time as it emphasizes the embodiment of knowledge, the materiality of affect, and the linguistic dimensions of subjectivity and sociality. The passage also suggests what moves Eva to begin writing a diary in English in Canada.

In the pages of her diary, Eva creates a writing identity and a persona who can maintain a critical distance to her new community: "(. . .) the diary is an earnest attempt to create a part of my persona that I imagine I would have grown into in Polish." She explains: "The diary is about me and not about me at all" (Hoffman 1998 [1989]: 121). This "me and not (. . ) me" is figured in the autobiography in the dialogues between two identities, one being a version of the "Cracow Ewa" and the other of the "Canadian Eva." While the autobiography does not "reproduce" pages of the diary, where, Hoffman says, she cannot use the word "I" in English, but instead is "driven (...) to the double, the Siamese-twin "you" (1998 [1989]: 121), it does present dialogues between these personas, beginning in the "Exile" section and continuing to the end. In these dialogues, the address of "you" is dominant, as the personas speak to each other and, it becomes clear, compete for recognition and dominance. Dialogues about the past and its relation to present realities, including identity, stage multiple perspectives which, to borrow Boym's terms, counteract restorative nostalgia and enable reflection. Even more than the dialogues, the English-language diary affords Ewa/Eva an orientation that is neither assimilative nor restoratively nostalgic; it enables her to remain out of line, in a position of "cultural negative capability" (1998 [1989]: 121), to resist assimilation by performing her difference from both her past in Cracow and her present Polish-Canadian/Canadian community. In the Canada/Exile section of Lost in Translation, Eva's diasporic feelings, which include a longing for home but also a stubborn, uncomfortable insistence upon "foreign" values, or values foreign to Canada and the Polish community in Vancouver, help her resist assimilation and impel her into writing. Precisely because English is foreign, using it in her diary provides Eva with the distance to observe critically, to write with

can emerge: "There is a political struggle about how we attribute good and bad feelings" (2010: 39). She finds that there is a strong assumption, or cultural given, "that bad feelings are backward and conservative and good feelings are forward and progressive. Bad feelings are seen as orientated toward the past, as a kind of stubbornness that 'stops' the subject from embracing the future. Good feelings are associated here with moving up and getting out" (2010: 50). 
"objectivity," and to express abstract thought more easily than emotion.

Yet, we do not have Eva's diary in the pages of this book; we have Hoffman's autobiography, which displays Hoffman's mastery of English prose - a prose which displays intellectual precision at the same time as it is highly poetic and lyrical. In her assessment of Lost in Translation, Levine suggests that Hoffman's writing may somehow not be "Polish" enough, and she faults Hoffman's work for over-intellectualization, for alternating between lyrical and "coolly cerebral" styles, and for "flaunting" her power over language (2003: 223). ${ }^{14}$ But the various registers of the text raise important questions; if the diary, with its "objective" prose, constitutes a site of cultural critique and resistance to assimilation, what are we to make of the autobiography's poetic qualities? Does the appearance of lyrical language mark a surrender of cultural opposition, and therefore a closer alignment with the affective communities she resisted in "Exile"? At the end of the autobiography, are we to read Hoffman/Eva as assimilated to US culture, as a "successful immigrant"?

One of the key passages in considering such questions occurs at the very end of the book, when Eva has successfully embarked on a publishing career in New York. Ending with the words, "I am here now" (Hoffman 1998 [1989]: 280), the final meditation appears to affirm Hoffman's regaining of paradise, of the fullness of a moment. In a garden in Cambridge, Hoffman hears her friend present the English names of flowers, and, repeating them, she finds that:

\begin{abstract}
they fit the flowers perfectly (...). For now, there are no Platonic azaleas, no Polish hyacinths against which these are compared. I breathe in the fresh spring air. Right now, this is the place where I'm alive. How could there be any other place? Be here now, I think to myself in the faintly ironic tones in which the phrase is uttered by the likes of me. Then the phrase dissolves. The brilliant colors are refracted by the sun. The small space of the garden expands into the dimensions of peace. Time pulses through my blood like a river. The language of this is sufficient. I am here now. (Hoffman 1998 [1989]: 280)
\end{abstract}

Specifically analyzing this passage, Lena Karlsson argues that in spite of Hoffman's musings on double-consciousness and the divided immigrant self, "what comes across the strongest is the desire for stable absolutes, suggested in her choice of title (. . .) and reinforced in her closing remark, 'I am here now." (2001: 66). Phillips Casteel finds the "affirmative and amnesiac conclusion" (2001:298) to be qualified by an understanding of double emigration and of the negative construction of Canada as a precondition for Hoffman's US assimilation. MacPherson arrives at a different conclusion: Hoffman's autobiography "engages with the myth of wholeness"

14 She writes that Hoffman "has become one of the most respected and recognized Polish voices in America - although how 'Polish' that American-trained voice really is may be a matter of some dispute" (Levine 2003: 217). 
only to underscore, through her underlying ironic voice, the illusionary qualities of childhood and of uncritical views of essential identity (2008: 95). MacPherson, then, associates a postmodern understanding of identity with Hoffman's ironic, critical prose, rather than with the lyrical elements, which Karlsson views as dominant, and redolent of a conservative, modernist understanding of identity.

Yet, Lost in Translation constructs diasporic feeling, including nostalgia, as a site of resistance and critique. Moreover, as initially noted, it is poetry that Hoffman associates with nostalgia, that "lyrical emotion" (Hoffman 2006: 14). In Lost in Translation, Hoffman writes: "Nostalgia is a source of poetry (. . .)" (1998 [1989]: 115). While, in the final section of the autobiography, Eva suggests that exile might be "the archetypal condition of contemporary lives," and her "very uprootedness" and "acute sense of dislocation" (Hoffman 1998 [1989]: 197) might be what unite her with a generation of Americans, her relation to her Eastern European past and her experience of dislocation provide her with the resources for resisting complete assimilation. She finds it ironic that "one of the ways in which I continue to know that I'm not completely assimilated is through my residual nostalgia - which many of my friends find a bit unseemly, as if I were admitting to a shameful weakness - for the more stable, less strenuous conditions of anchoring, of home" (197). In other words, even in the US, nostalgia allows her to perform her diasporic difference. Ultimately, and surprisingly, she performs difference through her use of poetic language.

Although writing about the lyric proper, Jonathan Culler's remarks are nevertheless apposite to the poetic and lyrical qualities of Lost in Translation, as well as to its thematic concerns with translation and the linguistic construction of identity. Culler emphasizes the performative aspects of lyric, as well as the ways that lyric foregrounds language: "Lyric is the foregrounding of language, in its material dimension, and thus both embodies and attracts interest in language and languages - in the forms, shapes, and rhythms of discourse" (2008: 205). Culler here echoes the Russian formalist notion of the defamiliarization of language, a concept that readily describes Hoffman's experience of her new, foreign language, but he also stresses the materiality of lyrical language. ${ }^{15}$

To return to the final sentence of Lost in Translation, I would like to follow the idea that Karlsson introduces but rejects - that the line might be read with a stress that emphasizes transience: "I am here now." Such an emphasis can be seen as a result of Hoffman's poetic use of language, for, according to Culler, the extravagance of lyrical language forges "special tenses, such as the lyric present (...). The special

15 It is appropriate that a reading of T.S. Eliot's poetry eventually marks an important moment in her life in a new language: "Words become (. . .) beautiful things (. . .) crosshatched with a complexity of meaning, with the sonorities of felt, sensuous thought" (1998 [1989]: 186). 
language of lyric generates this distinctive lyric temporality" (2008: 205). ${ }^{16}$ Moreover, as Culler puts it, "If narrative is about what happens next, lyric is about what happens now - in the reader's engagement with each line - and teachers and scholars should celebrate its singularity, its difference from narrative" (2008: 202). Though Hoffman's work is obviously an autobiographical narrative, and although it engages with personal and collective history, its conception of nostalgia and association of it with poetic language makes room for the rich complexity of diasporic feeling. I would suggest, finally, that the now is not the realization of full being, but the precarious moment of writing, of writing that is lyrical, full of affect, orienting both writer and readers toward an appreciation of the pastness of the past and of the imaginative, utopian dimensions of any home. ${ }^{17}$ Lyricism in this text complements a reflective nostalgia which, Boym explains, constantly defers homecoming. In writing about being "here now," Hoffman can be seen as writing about being no where, for, as Friedman expresses it, "Home is utopia - a no place, a nowhere, an imaginary space longed for, always already lost in the very formation of the idea of home." However, "With another slight shift, no where morphs into now here. Home is now here and no where at one and the same time" (2004: 192). This dialectic movement between "now here" and "no where" is achieved through Hoffman's use of lyricism, which risks being dismissed as a form of restorative nostalgia, but which, in my view, precariously holds the inevitable ambivalences involved in diasporic feeling.

\section{REFERENCES}

Ahmed, Sara. 2010. Happy objects. In Melissa Gregg and Gregory J. Seigworth (eds.), The affect theory reader, 29-51. Durham: Duke University Press.

Angé, Olivia and David Berliner. 2015. Introduction: Anthropology of nostalgia—anthropology as nostalgia. In Olivia Angé and David Berliner (eds.), Anthropology and nostalgia, 1-16. New York: Berghahn.

Baranczak, Stanislaw. 1990. Breathing under water and other East European essays. Cambridge: Harvard UP.

Berberich, Christine, Neil Campbell \& Robert Hudson. 2013. Affective landscapes: An introduction. Cultural Politics 9(3). 313-322.

16 Culler also writes that

If we believe language is the medium for the formation of subjectivity, lyric ought to be crucial, as the site where language is linked not only to structures of identification and displacement before the consolidation of subject positions but especially to rhythm and the bodily experience of temporality, on the one hand, and to the formative dwelling in a particular language, on the others. Narrative structures are translatable, but lyric, in its peculiar structural patterning, figures the givenness, the untranscendability, of a particular language, which seems to its users a condition of experience. (2008: 205)

17 Hoffman notes (taking issue with that exemplar of the American dream, Jay Gatsby) in Exit into History, "Except on the page, the past can never be recaptured, or repeated (. . .)." (1993: 97). 
Boym, Svetlana. 2001. The future of nostalgia. New York: Basic Books.

Culler, Jonathan. 2008. Why lyric? PMLA 123(1). 201-206.

Dancus, Adriana Margareta. 2011. Diasporic feeling and displaced nostalgia: A case study: Importeksport and Blodsbåxnd [sic]. Scandinavian Studies 83(2). 247-266.

Fjellestad, Danuta Zadworna. 1995. The Insertion of the self into the space of borderless possibility: Eva Hoffman's exiled body. MELUS 20(2). 133-147.

Friedman, Susan Stanford. 2004. Bodies on the move: A poetics of home and diaspora. Tulsa Studies in Women's Literature 23(2). 189-212.

Gitenstein, Barbara R. 1997. Eva Hoffman: Conflicts and continuities of self. In Thomas S. Gladsky and Rita Holmes Gladsky (eds.), Something of my very own to say: American women writers of Polish descent (East European Monographs CDXCIV), 261-76. Boulder, Colorado [New York]: distributed by Columbia University Press.

Herman, David. 2005. Yesterday's self: Nostalgia and the immigrant identity. Symploke 13(1-2). 360-362.

Hirsch, Marianne. 1994. Pictures of a displaced girlhood. In Angelika Bammer (ed.), Displacements: Cultural identities in question, 71-89. Bloomington: Indiana University Press.

Hirsch, Marianne and Leo Spitzer. 2002. "We would not have come without you": Generations of nostalgia. American Imago 59(3). 253-76.

Hoffman, Eva. 1993. Exit into history: A journey through the new Eastern Europe. New York: Penguin.

Hoffman, Eva. 1998 [1989]. Lost in translation: A life in a new language. London: Vintage.

Hoffman, Eva. 2013. Out of exile: Some thoughts on exile as a dynamic condition. European Judaism 46(2). 55-60.

Hoffman, Eva. 2006. The uses of the past. In Vesna Goldsworthy (ed.), Writing worlds 1: The Norwich exchanges, 13-19. Norwich: Pen \& Inc Press.

Jameson, Fredric. 1991. Postmodernism or, the cultural logic of late capitalism. Durham: Duke University Press.

Karlsson, Lena. 2001. Multiple affiliations: Autobiographical narratives of displacement by (im)migrant US women (Skrifter från moderna språk 2). Umeå: Umeå University.

Levine, Madeline. 2003. Eva Hoffman: Forging a postmodern identity. In Halina Stephan (ed.). Living in translation: Polish writers in America, 215-233. Amsterdam: Rodopi.

Macpherson, Heidi Slettedahl. 2008. "There is no world outside the text": Transatlantic slippage in Eva Hoffman's Lost in translation. In Transatlantic Women's Literature, 87-105. Edinburgh: Edinburgh University Press.

Matt, Susan J. 2011. Homesickness: An American history. Oxford: Oxford University Press.

Phillips Casteel, Sarah. 2001. Eva Hoffman's double emigration: Canada as the site of exile in Lost in translation. Biography 24(1). 288-301.

Scanlan, Sean. 2004. Introduction: nostalgia. Iowa Journal of Cultural Studies 5. 3-9. ir.uiowa.edu. (accessed 27 April, 2015. )

Stephan, Halina (ed.). 2003. Living in translation: Polish writers in America. Amsterdam: Rodopi.

Stephan, Halina. 2003. Introduction: The last exiles. In Halina Stephan (ed.). Living in translation: Polish writers in America, 7-28. Amsterdam: Rodopi.

Todorova, Maria. 2010. Introduction: From utopia to propaganda and back. In Maria Todorova and Zsuzsa Gille (eds.), Post-communist nostalgia, 1-13. New York: Berghahn 